\title{
MODELING THE POST-YIELD FLOW BEHAVIOR AFTER NEUTRON AND ELECTRON IRRADIATION OF STEELS AND IRON-BASE ALLOYS
}

R.J. DIMELFI*, D.E. ALEXANDER** AND L.E. REHN**

*Reactor Engineering Division, Argonne National Laboratory, Argonne, IL 60439, dimelfi@ anl.gov

**Materials Science Division, Argonne National Laboratory, Argonne, Il 60439

\section{ABSTRACT}

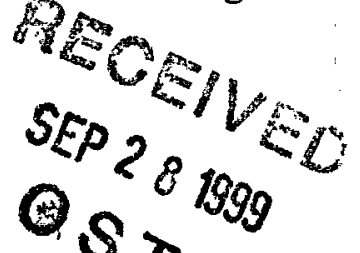

Irradiation hardening is an issue of practical importance as it relates to the remanentife and the nature of failure of reactor components exposed to displacement-producing radiation. For example, irradiation-induced yield strength increases in pressure vessel steels are directly related to increases in the ductile-to-brittle-transition-temperature of these materials. Other issues associated with hardening, such as reductions in ductility, toughness and fatigue life of structural steels are also of concern. Understanding these phenomena requires studies of fundamental microstructural mechanisms of hardening. Because of the limited supply of neutron-irradiated surveillance material, difficulties posed by the radioactivity of neutron-exposed samples and the uncertainty of irradiation conditions in this case, fundamental studies are often conducted using well-controlled experiments involving irradiation by electrons instead of neutrons. Also, in such studies, simple model alloys are used in place of steels to focus on the influence of specific alloy constituents. It is, therefore, important to understand the relationship between the results of this kind of experiment and the effects of in-reactor neutron exposure in order to use them to make predictions of significance to reactor component life. In this paper, we analyze the tensile behavior of pressure vessel steels (A212B and A350) irradiated by neutrons and electrons. The results show that the post-yield true stress/true strain behavior can provide fingerprints of the different hardening effects that result from irradiation by the two particles, which also reflect the influence of alloy content. Microstructurallybased models for irradiation-induced yield strength increases, combined with a model for strain hardening, are used to make predictions of the different effects of irradiation by the two particles on the entire flow curve that agree well with data.

\section{INTRODUCTION}

Irradiation hardening of structural steels is an important area of research in irradiation-effects science. This hardening can be the source of severe embrittlement of reactor pressure vessel (RPV) steels by virtue of the increase in the ductile-to-brittle-transition-temperature (DBTT) that it causes in them. Even under conditions, and in alloys, where brittle fracture is not produced by irradiation hardening, the reduction in useful ductility that it causes can lead to lower fracture toughness and shortened fatigue life. Because of these important effects, research in this area has gone on for many years [1-5]. Early studies [6,7] broadly revealed the nature of irradiation hardening as the result of increased lattice resistance to dislocation motion caused by a fine distribution of irradiation-produced defects arrayed as obstacles in the slip plane. These studies resulted in the development of models that are useful for making broad semi-quantitative predictions of yield strength increases associated with a given irradiation dose. Recent studies, utilizing more advanced experimental and computational tools have advanced the state of knowledge in this field, resulting in a more microstructurally mechanistic understanding. These studies focused on such finer-scale issues as the composition of irradiation produced defects [8], the evolution of defect microstructure [9], the different hardening levels produced by the presence of different alloy constituents [10], the effects 


\section{DISCLAIMER}

This report was prepared as an account of work sponsored by an agency of the United States Government. Neither the United States Government nor any agency thereof, nor any of their employees, make any warranty, express or implied, or assumes any legal liability or responsibility for the accuracy, completeness, or usefulness of any information, apparatus, product, or process disclosed, or represents that its use would not infringe privately owned rights. Reference herein to any specific commercial product, process, or service by trade name, trademark, manufacturer, or otherwise does not necessarily constitute or imply its endorsement, recommendation, or favoring by the United States Government or any agency thereof. The views and opinions of authors expressed herein do not necessarily state or reflect those of the United States Government or

any agency thereof. 


\section{DISCLAIMER}

Portions of this document may be illegible in electronic image products. Images are produced from the best available original document. 
of different irradiating particles [11], the recently-uncovered embrittlement produced by gamma-ray exposure [12], and the effects of annealing [13,14]/ageing[15] on irradiaion-produced microstructures and embrittlement. These studies have been conducted using well-controlled electron [12,16] and ion [10] irradiations of pressure vessel steels and specially-prepared simple model alloys in conjunction with studies of in-reactor neutron-exposed RPV steel surveillance material and neutron irradiated alloys. A review of some of the recent advances in this field can be found in Ref. 17.

We have been interested $[11,18]$ in understanding the differences in irradiation hardening effects between electron and neutron exposure. Understanding these differences is important because electron irradiations are performed to simulate the effects of in-reactor neutron exposure, and are used in fundamental studies of irradiation effects. Also, electrons produced by gamma ray exposure can cause hardening, resulting in the embrittlement of reactor structures that is additive to that produced by neutron exposure [12].

We have been conducting research $[11,18]$, in which we use the post-yield flow behavior of irradiated materials as a probe to reveal information about the nature of irradiation hardening. One observation we have made is that pronounced (70\%) increases in yield strength can be observed in RPV steels, even for irradiation exposures so low in dose $(<0.05$ displacements per atom, dpa) that the microstructural changes they produce are invisible to electron microscopic probes [19]. This observation implies that mechanical behavior can be used as a magnifying tool to study these effects. We suggest that, beyond just using the yield strength as a measure of irradiation hardening, the postyield flow behavior can be used to magnify the different hardening effects produce by different irradiating particles in materials with different alloy content. We anticipate that an analysis of the post-yield flow of irradiated materials will provide information complementary to that obtained by other methods.

In our earlier work [11], we found a clear and consistent difference between neutron and electron irradiated materials, even when, at similar dose levels both irradiations produced similar. yield strength increases. For example, neutron irradiation, under the conditions studied, appears to produce the same hardening effect as plastic deformation, i.e. strain hardening. This phenomenon is best exemplified graphically, as is shown in Fig.1. Figure la shows the true-stress true-strain curves for the RPV steel $\mathrm{A} 212 \mathrm{~B}$, neutron irradiated at $\mathrm{T}<60^{\circ} \mathrm{C}$ to the dose levels indicated. Each curve is drawn only to the extent of the maximum uniform strain (strain at maximum load). It can be seen that, with successively increasing dose, the yield strength increases and the uniform strain decreases, but the curves flatten so that the true stress at maximum load is the same for all the curves. The shape of the curves for irradiated material compared to that for the unirradiated case suggest that, if they were shifted along the strain axis, they would superimpose on the unirradiated-material flow curve. In Fig.1b, these shifts are made. It can be seen that all the curves fall along the unirradiated-material flow curve and end at essentially the same point: the same true-stress and truestrain at maximum load. This is precisely what would be the case if the hardening were accomplished by cold work (plastic straining) instead of neutron irradiation.

Electron irradiated material behaves differently. In Fig.2, we show the same alloy, electron irradiated at $\mathrm{T}<60^{\circ} \mathrm{C}$ to the dose levels indicated. We see that, with successively increasing dose, the yield strength increases. These strength increases are similar in magnitude to those achieved by neutron irradiation to similar dose levels. Also, the maximum uniform strain decreases somewhat with increasing electron-irradiation dose. However, unlike the case of neutron irradiation, the curves for electron-irradiated material do not flatten in a way that suggests that they would superimpose on the unirradiated material flow curve. In fact, it appears that electron irradiation of this alloy, for the conditions studied, effects a shift along the stress axis, i.e. reflecting "stress hardening" rather than strain hardening. We showed [18] very similar results with regard to the hardening differences 
produced by electron and neutron irradiation of the RPV steel A350 and of the binary alloys Fe$0.3 \mathrm{Cu}$ and $\mathrm{Fe}-0.7 \mathrm{Ni}$, though the distinction occurs to a lesser extent and is less clear in the binary alloys.
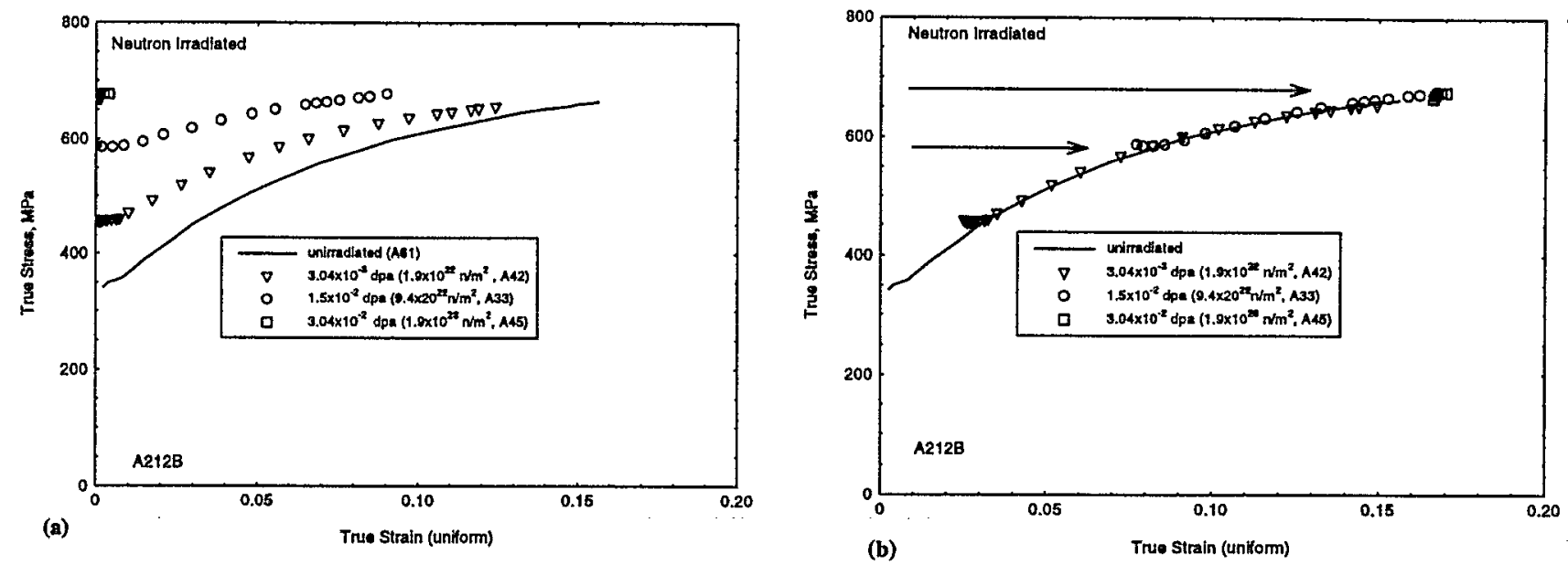

Fig. 1. (a) The flow behavior of $A 212 B$ neutron-irradiated for the conditions shown. (b) The flow curves for the irradiated material shifted parallel to the strain axis, showing that they superimpose on the curve for the unirradiated material.

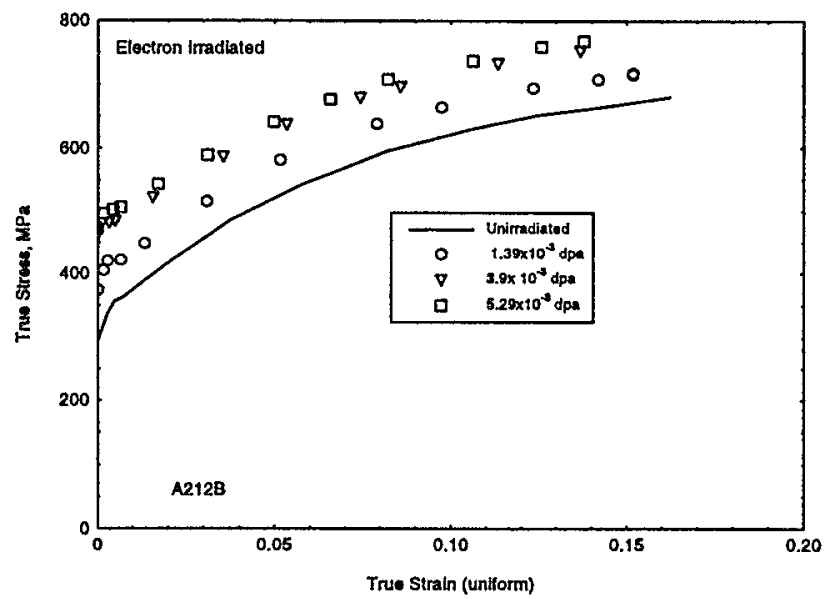

Fig. 2. The flow behavior of electron-irradiated A212B, showing that, at successively higher dose, the curves are shifted to higher stress levels and would not superimpose on the unirradiated-material flow curve, as is the case for neutron irradiated material.

We have suggested that these differences in flow behavior can provide insights into the nature of the defects that cause irradiation hardening in these two cases and information that is complementary to that provided by the mechanistic studies discussed earlier. In this paper, we offer models for these behaviors that connect them to the microstructural aspects of irradiation hardening. 


\section{ANALYSIS}

The observations regarding irradiation hardening by the two particles are general, and are particularly apparent in the two pressure vessel steels studied. All of the flow curves showing the general hardening behaviors are shown in Ref.18. In order to display these general behaviors and guide our modeling discussion, we refer to Fig. 3.
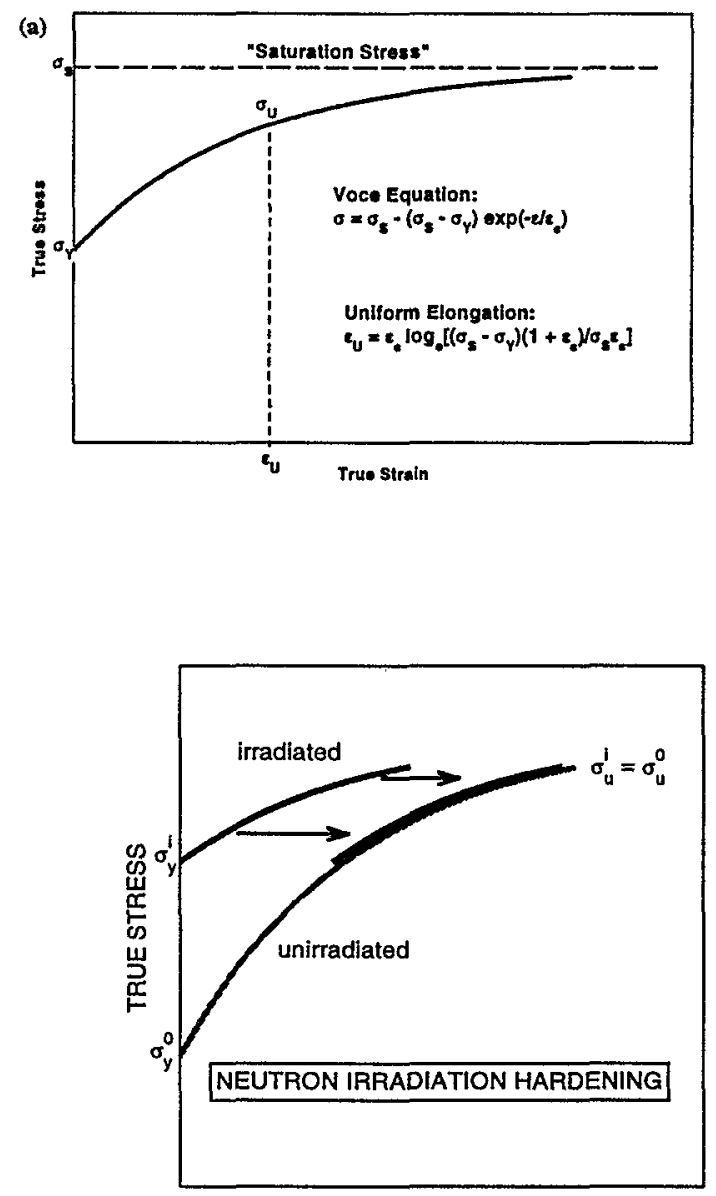

(b)

TRUE STRAIN (UNIFORM ONLY)
Fig. 3. (a) A schematic showing the Voce equation that we use to model the flow behavior of materials, which features a saturation stress approached at large plastic strain. (b) A schematic indicating that neutronirradiation hardening is similar to strain hardening. (c) A schematic, indicating that electron-irradiation hardening can be viewed to cause a shift along the stress axis of the unirradiated-material flow curve.

Since it appears that we can reference the flow behavior of the irradiated material to that for the unirradiated material, we must first describe the true-stress true-strain behavior of the unirradiated material. Figure 3a depicts, schematically, our observation that for all the materials studied the flow stress, $\sigma$, approaches a saturation value, $\sigma_{\mathrm{S}}$, with increasing plastic strain. The equation that models this behavior is that of Voce [20], which has the form:

$$
\sigma=\sigma_{s}-\left(\sigma_{s}-\sigma_{Y}\right) \exp \left(\frac{-\varepsilon}{\varepsilon_{c}}\right)
$$

In this equation, $\sigma_{\mathrm{Y}}$ is the yield stress, $\varepsilon$ is the plastic strain, and $\varepsilon_{\mathrm{c}}$ is a constant related to the initial 
strain-hardening rate. This equation is representative of the concept that, as the dislocation density increases during plastic deformation and the material becomes harder, a state is reached where further increases in stored elastic strain energy from new dislocation generation are sufficient to drive dynamic recovery and the elimination of dislocations. Natural consequences of this are the approach to a steady state or saturation stress and a continually decreasing hardening rate. Since saturation is also a feature of the observed irradiation hardening phenomena, we feel that this equation is a particularly appropriate model to be used here. The true strain associated with maximum uniform elongation, $\varepsilon_{\mathrm{U}}$, can be obtained from Eq.(1) and the condition of maximum load,

$$
\varepsilon_{U}=\varepsilon_{c} \log _{e}\left[\left(\sigma_{S}-\sigma_{Y}\right)\left(1+\varepsilon_{c}\right) / \sigma_{S} \varepsilon_{c}\right] .
$$

Therefore, in this model, if $\sigma_{\mathrm{S}}-\sigma_{\mathrm{Y}}$ is constant, $\varepsilon_{\mathrm{U}}$ decreases with increasing saturation stress. It will be seen later that this fact is relevant with regard to electron-irradiation hardening.

Figures $3 \mathrm{~b}$ and $3 \mathrm{c}$ show, schematically, the general behaviors associated with neutron and electron irradiation hardening, respectively. From these figures, it is clear that, if we have an equation that describes the yield strength increase resulting from irradiation, then we can determine the entire flow behavior of the irradiated material. For the case of neutron irradiation, the remaining part of the flow curve (post-yield) is the same as that of the unirradiated material starting at the higher yield stress. From these results, we can predict the strength and hardening rate at any value of strain, and the uniform elongation, of the neutron irradiated material. For the case of electron irradiated material, the entire flow curve of the unirradiated material is shifted along the stress axis by the amount of the yield strength increase caused by the irradiation. The predicted maximum uniform elongation of the electron-irradiated material is decreased in accordance with Eq.(2) because $\sigma_{s}$ is increased in this case. Once again, all the features of the flow behavior of the electron irradiated material can be determined if we have a model for the yield strength increase.

Because saturation of the yield strength increase is a common feature we have observed for the conditions and alloys studied, we resort to the theory proposed by Whapham and Makin [21] (WM) for irradiation-induced yield strength increases by lattice hardening. In this theory, irradiationproduced defects act as obstacles to dislocation glide. At low dose, the obstacle density increases linearly with dose. The yield strength increment is expected to be proportional to the reciprocal of the mean obstacle spacing, i.e. proportional to the square root of the obstacle density and, hence proportional to the square root of the irradiation dose. At high dose, existing obstacles capture newly produced defects. Hence, the obstacle density saturates as does the yield strength increment. The resulting equation for the yield strength increment, $\Delta \sigma_{\mathrm{Y}}$, is,

$$
\Delta \sigma_{Y} \equiv \sigma_{Y}{ }^{I}-\sigma_{Y}{ }^{0}=\Delta \sigma_{Y}{ }^{s a t}\left[1-\exp \left(-\frac{\phi}{\phi_{0}}\right)\right]^{\frac{1}{2}},
$$

where $\sigma_{\mathrm{Y}}{ }^{0}$ is the yield strength of the unirradiated material, $\sigma_{\mathrm{Y}}{ }^{\mathrm{I}}$ is the yield strength of the irradiated material, $\Delta \sigma_{Y}$ sat is the saturation value of the yield strength increment, $\phi$ is the irradiation dose and $\phi_{0}$ is a scaling factor.

Figure 4 shows a graph of the yield strength increment as a function of dose for irradiated A212B. The data are for both electron and neutron-irradiated material. The data shown are tabulated elsewhere [12], but include the yield stress values plotted in Figs. 1a and 2, which show a limited amount of data for the purposes of clarity. In Fig. 4, the yield strength increments are 
plotted normalized by their saturation values. The neutron irradiated material data (open symbols) are fit with Eq.(3) (dashed curve) under the constraint that $\Delta \sigma_{Y}{ }^{\text {sat }}$ is equated to the factor $\sigma_{S}-\sigma_{Y}$ from the Voce model [Eq.(2)], since we take irradiation hardening to be equivalent to strain hardening in this case.

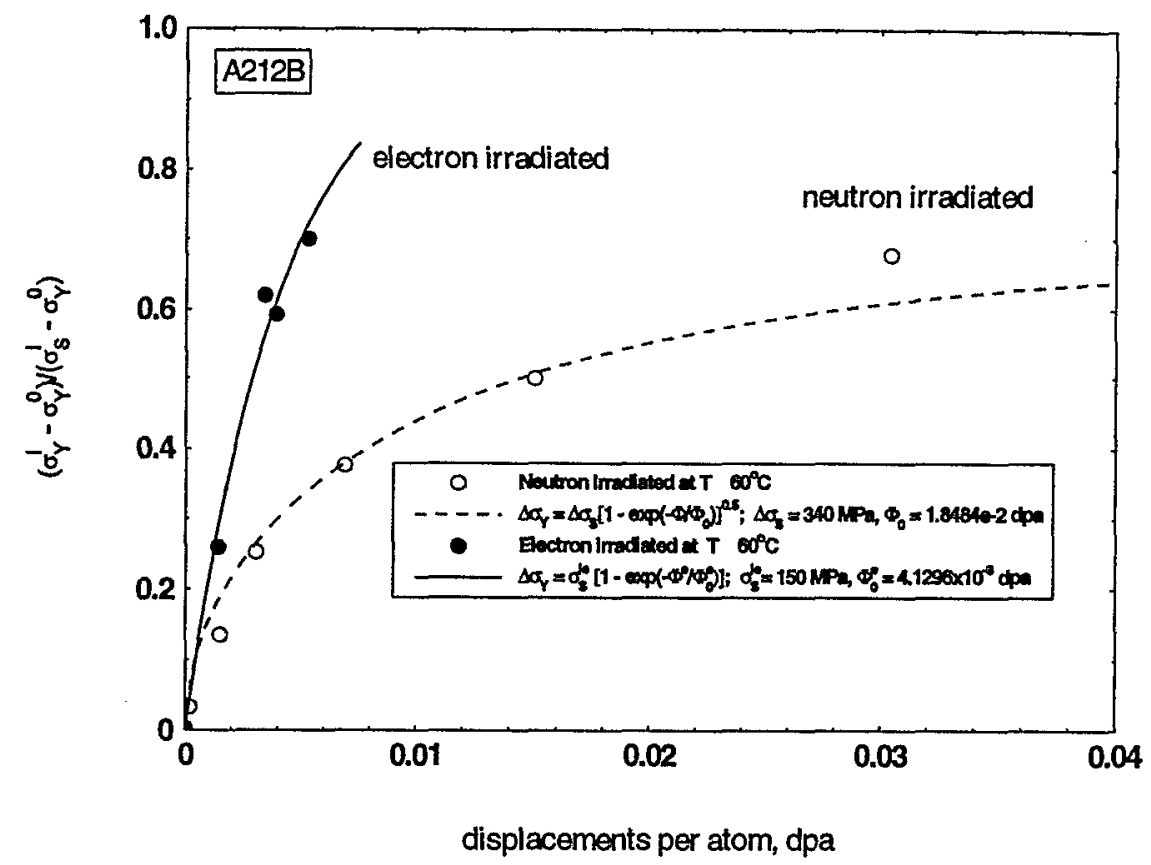

Fig.4. Yield strength increments, normalized by their saturation values, for neutron and electron irradiated A212B for the conditions shown, plotted as a function of irradiation dose in dpa. The neutron-irradiated material data are fit with the W-M model. The electron-irradiated material data are fit with a similar model, but which is linear in dose at low dose.

It was found that the electron irradiated material data could not be well fit with a parabolic dose dependence [Eq.(3)] at low dose, but rather better by an equation similar in form but which displays a linear dose dependence at low dose:

$$
\Delta \sigma_{Y} \equiv \sigma_{Y}^{I}-\sigma_{Y}{ }^{0}=\Delta \sigma_{Y}{ }^{s a t}\left[1-\exp \left(-\frac{\phi}{\phi_{0}}\right)\right] \text {. }
$$

This result is consistent with a theory proposed by Mott [22] for hardening by a closely-spaced distribution of very small coherent precipitates, in which the yield strength increase is proportional to the density of precipitates rather than the square root of the density. In Fig. 4, the electronirradiated material data (solid symbols) are fit with Eq.(4) (solid line), and in this case, the saturation yield strength increment is left as a fitting parameter, since, for electron-irradiation, the hardening does not appear to be equivalent to strain hardening. Figure 5 shows a similar plot for the RPV steel A350. The linear dose dependence at low dose for electron irradiated material allows the yield strength increment to approach its saturation level faster than is the case for neutron irradiation. In that sense, electron irradiation appears more efficient at hardening than neutron irradiation, which is consistent with earlier our observations [16]. 


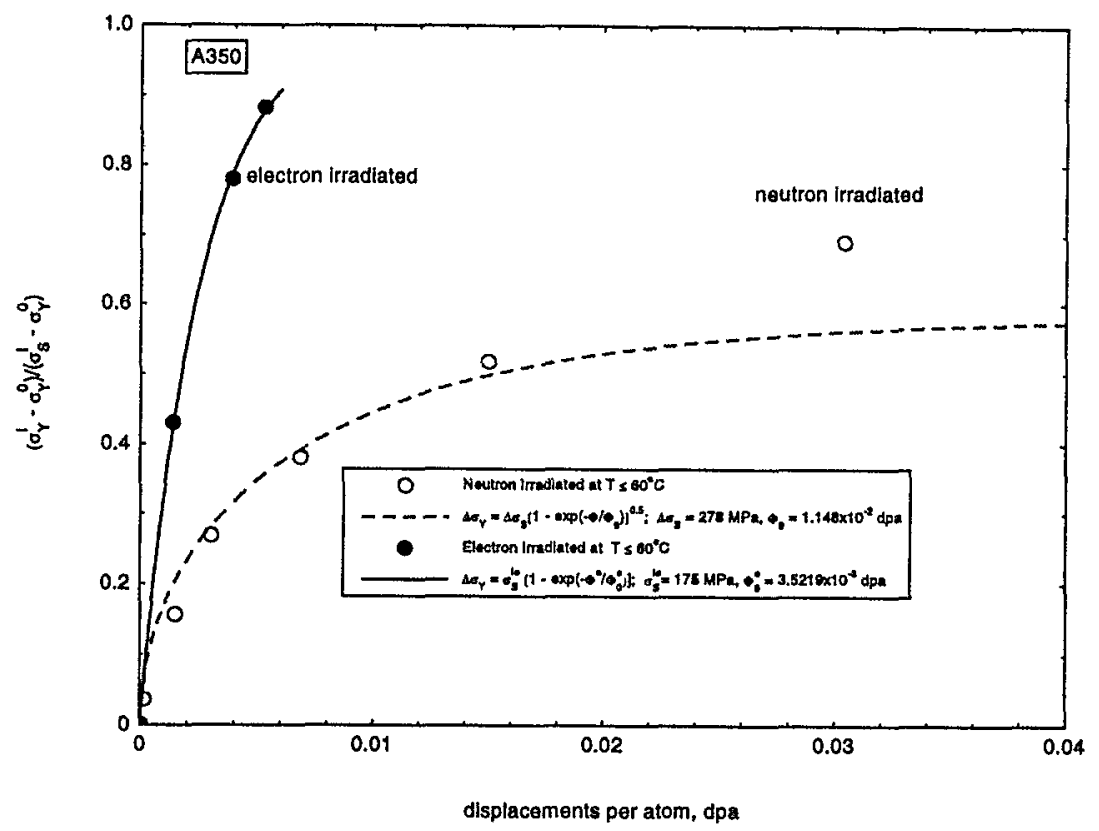

Fig. 5. The same as Fig. 4 for the RPV steel A350

\section{RESULTS}

In order to model the flow behavior of neutron irradiated material, we combine Eq.(3) with the Voce model, where we add a term to the argument of the exponential to account for the effective strain, $\varepsilon$, that we associate with irradiation hardening. The Voce-type equation then has the form:

$\sigma=\sigma_{s}-\left(\sigma_{s}-\sigma_{Y}\right) \exp \left(-\frac{\varepsilon+\varepsilon^{l}}{\varepsilon_{c}}\right)$

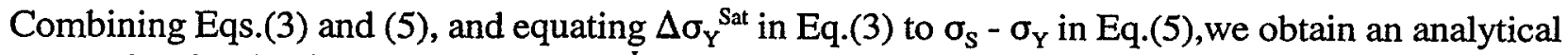
expression for the dose dependence of $\varepsilon^{I}$. Hence, for a given neutron-irradiation dose, we calculate $\varepsilon$, substitute it into the Voce model for the unirradiated material and predict the flow behavior for the material irradiated to that dose level. Figure 6a shows the results obtained for A212B. The solid curve drawn through the solid symbols (data) is the Voce fit for the unirradiated-material flow behavior. The open symbols shown are the irradiated-material data that is also shown in Fig. 1a. The dashed curves are the predictions for the flow behavior made as described above for the dose levels indicated. All the data and curves are drawn only to the maximum uniform strain for the data. The arrows on the graph indicate the predicted [Eq.(2)] values of the maximum uniform strain for each curve. Figure 6 b shows similar results obtained for neutron irradiated A350. 

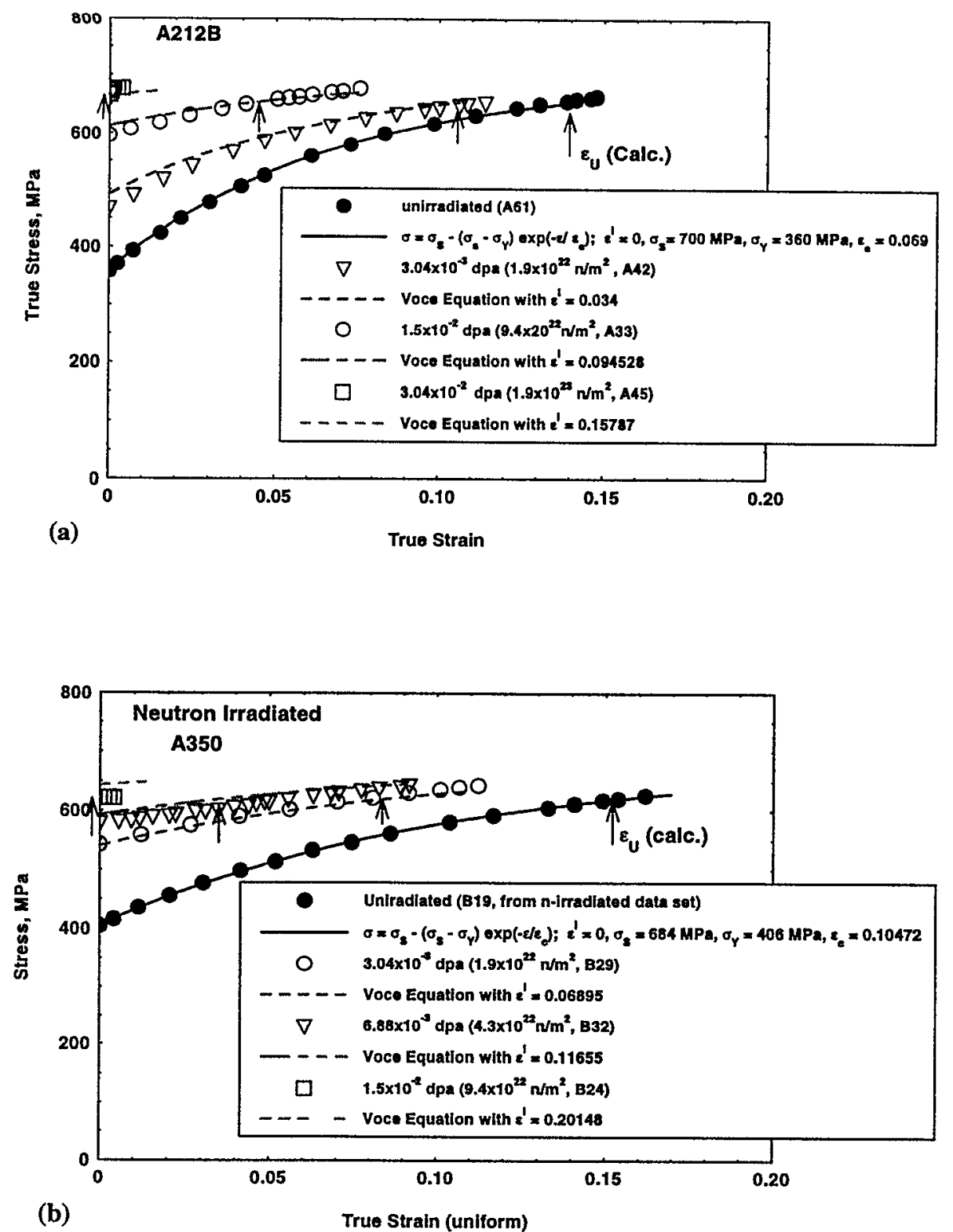

Fig. 6. Models for the flow behavior of neutron-irradiated (a) A212B and (b) A350. The yield strength increases as a function of dose are calculated with the W-M model, and the flow behavior is determined by substituting an effective plastic strain to represent irradiation hardening in the Voce equation as described in the text.

In order to model the flow behavior of electron irradiated material, we use Eq.(4) to determine the yield strength increment for a given dose level. We then shift the entire unirradiatedmaterial flow curve along the stress axis by that amount. Figure 7 a shows the results obtained for electron irradiated A212B. Once again, each curve is shown only to the extent of maximum uniform strain for the data. The arrows on the graph show the predicted values of $\varepsilon_{\mathrm{U}}$ for each curve. Figure $7 \mathrm{~b}$ shows similar results obtained for electron irradiated A350. 

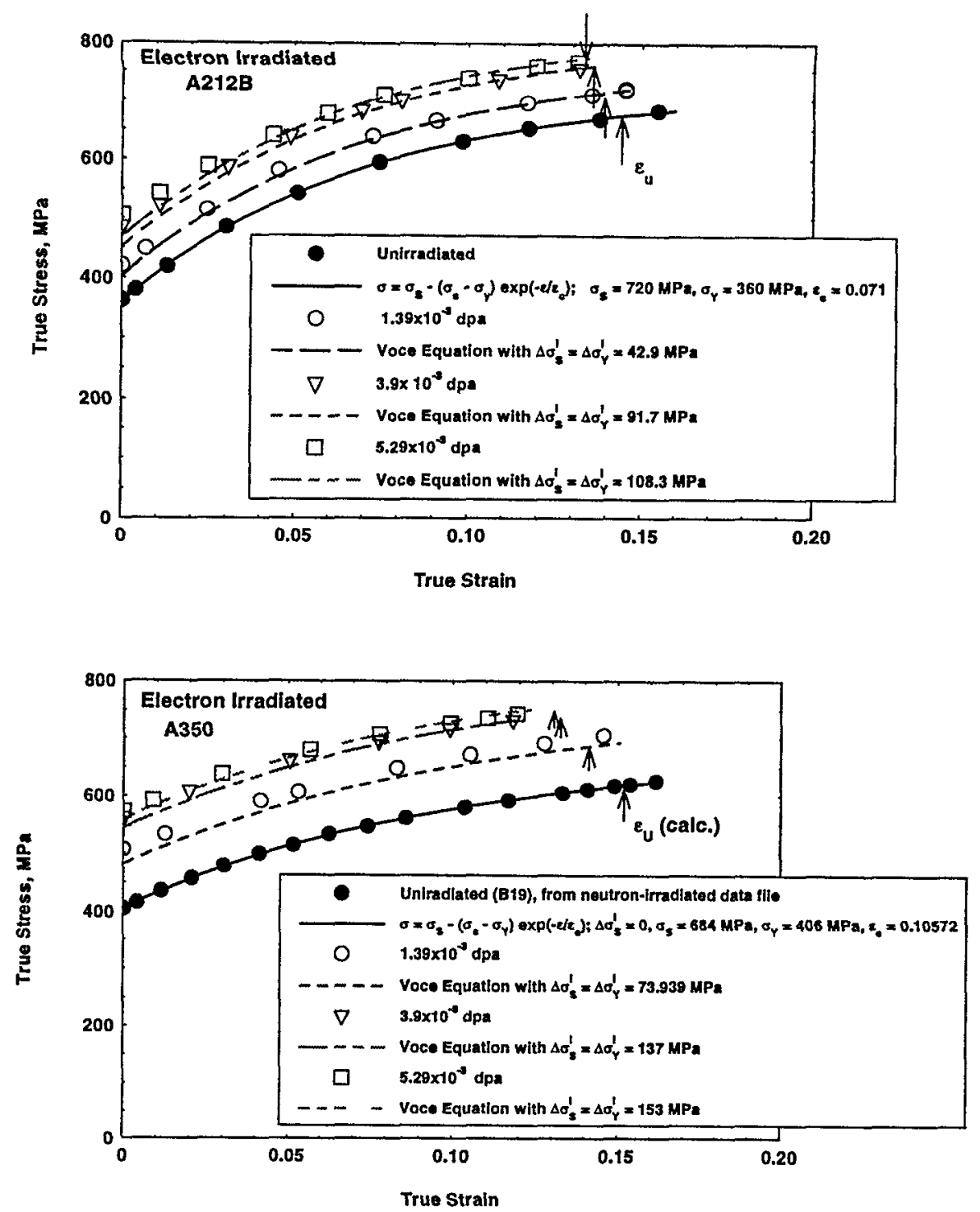

Fig. 7. Models for the flow behavior of electron-irradiated (a) A212B and (b) A350. The yield strength increment is calculated using Eq.(4), and the post-yield flow behavior is determined by shifting the entire unirradiated-material flow curve by the yield strength increment.

\section{CONCLUSIONS}

The post-yield flow behavior of neutron irradiation hardened RPV steels A212B and A350 can be well-described by using the model derived by Whapham and Makin for the dose dependence of the yield strength increment in combination with a Voce-type equation for the strain hardening behavior of the unirradiated material. Good agreement between the model and data was achieved when the saturation yield-strength increment in the W-M model was related directly to the saturation stress in the Voce model, which resulted in a representation of irradiation hardening by an effective plastic strain. This result implies that neutron irradiation hardening can, indeed, be viewed as having the same effect as strain hardening under the conditions studied. This behavior can be the case if the neutron irradiation-produced defects are dislocation loops that act as barriers to the motion of existing glide dislocations, thereby increasing the yield strength, but which, after flow begins contribute to the glide dislocation density as though they were produced by straining. For the case of electron irradiation hardening of these same steels, good agreement with data was obtained when 
the yield strength increment was modeled by an equation similar to the W-M model, but with a linear dose dependence at low dose, consistent with a model for hardening by a fine distribution of coherent precipitates. In this case, the entire unirradiated material flow curve, still modeled by the Voce equation, was shifted along the stress axis by the calculated yield strength increment. This behavior can be the case if the electron irradiation-produced defects are coherent precipitates that offer a uniform increased resistance to the motion of existing glide dislocations without themselves contributing to the glide dislocation density. The linear dose dependence observed for electron irradiation hardening renders it a more efficient hardening process than neutron irradiation hardening, as the former approaches its saturation hardening level faster than the latter.

\section{ACKNOWLEDGMENT}

This work was performed under the auspices of the United States Department of Energy, and was supported by the U.S. Department of Energy Technology Support Programs and BES-Materials Sciences Programs under Contract No. W-31-109-ENG-38.

\section{REFERENCES}

1. A. Seeger, Proc. $2^{\text {nd }}$ United Nations Int. Conf. on the Peaceful Uses of Atomic Energy, Geneva, United Nations, New York, 1958, p. 250.

2. Donald R. Olander, Fundamental Aspects of Nuclear Reactor Fuel Elements, NTIS, Springfield, VA, 1976, pp. 418-462.

3. T.H. Blewitt, Dislocations and Mechanical Properties of Crystals, Ed. by J.C. Fisher, Wiley, New York, 1956, p.573.

4. D. Pachur, Proc. $10^{\text {th }}$ Int. Symp. On Effects of Radiation on Materials, ASTM STP 725, Ed. by D. Kramer, H.R. Brager and J.S. Perrin, Philadelphia, PA, 1981, p.5.

5. K. Farrell, S.Y. Mahmood, R.E. Stoller, L.K. Mansur, J. Nucl. Mater. 210, p. 268 (1994).

6. M.J. Makin and F.J. Minter, Acta Met. 8, p. 691 (1960).

7. M.J. Makin and T.H. Blewitt, Acta Met. 10, p. 241 (1962).

8. G.R. Odette, C.L. Liu, B.D. Wirth, Proc. Symp. On Microstructure Evolution During Irradiation, Ed. by I.M. Robertson, G.S. Was, L.W. Hobbs and T.D. de la Rubia, MRS, Pittsburgh, 1997, pp. 457-469.

9. G.R. Odette, Proc. Symp.on Microstructure of Irradiated Materials, Ed. by I.M. Roberston, L.E. Rehn, S.J. Zinkle and W.J. Phythian., MRS, Pittsburgh, (1994) pp. 137-148.

10. P.M. Rice and R.E. Stoller, J. Nucl. Mater. 244, pp 219-226 (1996).

11. R.J. DiMelfi, D.E. Alexander and L.E. Rehn, J. Nucl. Mater. 252, pp171-177 (1997).

12. D.E. Alexander and L.E. Rehn, J. Nucl. Mater. 217, p. 213 (1994).

13. P. Pareige, R.E. Stoller, K.F. Russel and M.K. Miller, J. Nucl. Mater. 249, pp. 165-174.

14. E.D. Eason, J.E. Wright, E.E. Nelson, G.R. Odette and E.V. Mader, Nucl. Eng. Des. 179, pp. 257-265.

15. P. Pareige, K.F. Russell, R.E. Stoller and M..K. Miller, J. Nucl. Mater. 250, pp.176-183 (1997).

16. D.E. Alexander, G.R. Odette, G.R. Lucas and L.E. Rehn, Proc. Symp. On Thermodynamics and Kinetics of Phase Transformations, Ed. J.S. Im, B. Park, A.L. Greer, G.B. Stephenson, MRS, Pittsburgh, PA, 1995, pp. 177-182.

17. C.A. English, W.J. Phythian, R.J. McElroy, Symp. On Microstructure Evolution During Irradiation, Ed. by I.M. Robertson, G.S. Was, L.W. Hobbs and T.D. de la Rubia, MRS, 
Pittsburgh, 1997, pp. 471-482.

18. R.J. DiMelfi, D.E. Alexander and L.E. Rehn, Proc. $6^{\text {th }}$ Int. Conf. on Nuclear Engineering, ICONE-6, ASME, New York, 1998, paper \#6079.

19. Oak Ridge National Laboratory Technical Report, ORNL/TM-10444, Evaluation of HFIR Pressure Vessel Integrity Considering Radiation Embrittlement, Ed. by R.D. Cheverton, J.G. Merkle and R.K. Nanstad, April, 1988, p. 118.

20. E. Voce, J. Inst. Met. 74 p.537 (1968).

21. A.D. Whapham and M.J. Makin, Phil. Mag. 5, p. 237 (1960).

22. N.F. Mott, J. Inst. Met.72, p. 367 (1946). 